\title{
Diagnosis Penyakit Jantung Menggunakan Adaptive Neuro-Fuzzy Inference System (ANFIS)
}

\author{
Khadijah Fahmi Hayati Holle, Resti Ludviani, and Laili Cahyani
}

\begin{abstract}
The number of uncertain risk factor in heart disease makes experts difficult to diagnose its disease. Computer technology in the health field is mostly used. In this paper, we implement a system to diagnose heart disease. The used method is Adaptive neuro-fuzzy inference system which combine the advantage of fuzzy and neural network. The used data is UCI Cleveland data that have 13 attributes as inputs. Output system diagnosis compared with observational data for evaluation. System performance tested by calculating accuracy. Tests were also conducted on the variation of the learning rate, iteration, minimum error, and the use of membership functions. Accuracy obtained from test is $65,657 \%$ where using membership function Beta.
\end{abstract}

Index Terms-Anfis, Hearth Disease, Neuro Fuzzy, UCI data.

Abstrak--Banyaknya faktor resiko yang tidak tentu pada penyakit jantung menjadikan para ahli kesulitan untuk melakukan diagnosis terhadap penyakit tersebut. Teknologi komputer di bidang kesehatan banyak digunakan. Pada paper ini, sebuah sistem diagnosis penyakit jantung diimplementasikan. Method yang digunakan adalah Adaptive neuro-fuzzy inference system yang mengkombinasikan keuntungan dari metode fuzzy dengan jaringan saraf tiruan. Data yang digunakan adalah data UCI Cleveland yang memiliki 13 atribut sebagai input. Output diagnosis sistem dibandingkan dengan data observasi sebagai evaluasi. Kinerja sistem diuji dengan perhitungan akurasi. Pengujian juga dilakukan terhadap variasi nilai learning rate, iterasi, eror minimum, dan penggunakan membership functions. Nilai akurasi yang diperoleh dari uji coba adalah $65,657 \%$ dengan menggunakan membership function Beta.

Kata Kunci-Anfis, data UCI, Neuro Fuzzy, Penyakit jantung

Khadijah Fahmi Hayati Holle is with the Infornatic Engineering Departement of UIN Maliki , Malang, Indonesia (email: khadijah.holle@gmail.com)

Resti Ludviani, is with Institute Technology of Sepuluh Nopember, Surabaya, Indonesia. (email: restiludvi@gmail.com).

Laili Cahyani was with Institute Technology of Sepuluh Nopember, Surabaya, Indonesia (email: chandlie@gmail.com).

\section{PENDAhUluan}

Saat ini penggunaan teknologi komputer dalam bidang kesehatan tentang diagnosis dan pengobatan penyakit sangat meningkat. Meskipun faktanya penggunaan teknologi komputer dalam bidang kesehatan memiliki kompleksitas dan ketidakpastian tinggi, sistem cerdas seperti logika fuzzy, jaringan saraf tiruan, dan algoritma genetik telah dikembangkan [1].

Pada ranah resiko penyakit jantung, rokok, kolesterol, tekanan darah, diabetes, jenis kelamin dan usia merupakan faktor resiko utama yang berpengaruh pada resiko penyakit jantung [2]. Karena banyak faktor resiko yang tidak pasti dalam resiko penyakit jantung, terkadang diagnosis penyakit jantung sangat sulit dilakukan oleh para ahli. Selain itu tidak ada batasan khusus antara apa yang dimaksud sehat dan sakit [3]. Oleh karena itu, perlu dikembangkan sebuah sistem otomatis yang akurat untuk memenuhi kebutuhan para ahli, sehingga dapat mempercepat proses diagnosis penyakit dan dapat melakukan pengobatan yang sesuai.

Beberapa metode telah diusulkan untuk melakukan diagnosis penyakit jantung, seperti: Ali dan Mehdi [4] pada tahun 2010 telah mengusulkan sebuah sistem diagnosis penyakit jantung menggunakan FES (Fuzzy Expert System), Anooj [5] pada tahun 2011 yang telah mengusulkan sistem pengambilan keputusan untuk prediksi resiko penyakit jantung menggunakan pembobotan aturan fuzzy. Namun, akurasi yang dihasilkan kurang baik. Pada tahun 2012, E. P. Ephzibah dan Dr. V. Sundarapandian [6] mengusulkan sistem diagnosis penyakit jantung menggunakan teknik Neuro-Fuzzy. Namun dalam paper tersebut, proses Neuro-Fuzzy tidak diperjelas. Selain itu, tahun 2013 Senthil Kumar menggunakan Advanced Fuzzy Resolution Mechanism untuk diagnosis penyakit jantung [7].

Melalui data yang digunakan pada penelitian sebelumnya, serta dengan menggabungkan dua sistem untuk penyelesaian masalah, yaitu sistem fuzzy dan sistem jaringan saraf tiruan diharapkan hasil yang dicapai nantinya dapat maksimal. Dasar dari penggabungan sistem ini adalah karena kelebihan dan 
kekurangan dari masing-masing sistem. Kemampuan jaringan saraf tiruan adalah mengenali sistem melalui proses pembelajaran untuk memperbaiki parameter adaptif. Kekurangan dari sistem ini adalah kerumitan strukturnya, sedangkan sistem fuzzy mempunyai konsep yang mirip dengan konsep berpikir manusia [8].

Oleh karena adanya manfaat dan keterbatasan yang ada pada setiap metode, maka pada paper ini diajukan sebuah sistem diagnosis penyakit jantung menggunakan Adaptive Neuro-Fuzzy Inference System (ANFIS) yang menggabungkan fuzzy inference system dengan jaringan saraf tiruan.

\section{DATASET}

Data yang digunakan dalam implementasi sistem diagnosis penyakit jantung menggunakan Adaptive Neuro-Fuzzy Inference System (ANFIS) ini didapatkan dari Cleveland dataset yang tersedia pada http://archive.ics.uci.edu/ml. Robert Detrano, M.D., Ph.D., mengumpulkan data-data tersebut pada V.A. Medical Centre.

Penelitian sesuai yang telah dipublikasikan menggunakan 14 dari 76 atribut yang ada pada database penyakit jantung di Cleveland. Keberadaan penyakit jantung pada pasien diindikasikan oleh sebuah nilai bilangan dari 0 (tidak ada penyakit) sampai 4 . Membedakan keberadaan penyakit (nilai 1-4) dari tidak adanya penyakit (nilai 0) telah difokuskan dalam penelitian menggunakan database Cleveland [9].

Pada penelitian ini, atribut yang digunakan untuk diagnosis penyakit jantung dari Cleveland dataset adalah sebagai berikut: usia, jenis kelamin $(1=$ male, $0=$ female), tipe nyeri dada, tekanan darah saat istirahat (mm Hg), kolesterol serum $(\mathrm{mg} / \mathrm{Cl})$, tekanan darah saat puasa > $120 \mathrm{mg} / \mathrm{dl}$, hasil elegtrokardiografi saat istirahat, detak jantung maksimum yang dicapai, exercise induced angina, ST depression yang diinduksi oleh latihan, the slope of the peak exercise ST segment, jumlah pembuluh darah besar, thal $(3=$ normal, $6=$ fixed defect, $7=$ reversable defect), hasil diagnosis penyakit jantung

\section{METODE}

\section{A. Inferensi Sugeno (TSK)}

Sistem inferensi Sugeno memiliki karakteristik yaitu konsekuen bukan merupakan himpunan fuzzy, namun merupakan suatu persamaan linier dengan variabelvariabel sesuai variabel inputnya. Metode ini diperkenalkan oleh Takagi-Sugeno Kang pada tahun 1985.

Ada 2 model untuk sistem inferensi fuzzy menggunakan metode TSK, yaitu model TSK orde 0 dan model TSK orde 1.

a. Secara umum bentuk model fuzzy TSK orde 0 adalah :

$\operatorname{IF}\left(\mathrm{x}_{1}\right.$ is $\left.\mathrm{A}_{1}\right) *\left(\mathrm{x}_{2}\right.$ is $\left.\mathrm{A}_{2}\right) *\left(\mathrm{x}_{3}\right.$ is $\left.\mathrm{A}_{3}\right) * \ldots *\left(\mathrm{x}_{\mathrm{n}}\right.$ is $\left.\mathrm{A}_{\mathrm{n}}\right)$ THEN $\mathrm{z}=\mathrm{k}$ b. Secara umum bentuk model fuzzy TSK orde 1 adalah :

$$
\begin{aligned}
& \operatorname{IF}\left(\mathrm{x}_{1} \text { is } \mathrm{A}_{1}\right) *\left(\mathrm{x}_{2} \text { is } \mathrm{A}_{2}\right) *\left(\mathrm{x}_{3} \text { is } \mathrm{A}_{3}\right) * \ldots *\left(\mathrm{x}_{\mathrm{n}} \text { is } \mathrm{A}_{\mathrm{n}}\right) \\
& \text { THEN } \mathrm{z}=\mathrm{p}_{1} * \mathrm{x}_{1}+\ldots+\mathrm{p}_{\mathrm{n}} * \mathrm{x}_{\mathrm{n}}+\mathrm{q}
\end{aligned}
$$

dengan $A_{i}$ adalah himpunan fuzzy ke-i sebagai anteseden, * adalah operator fuzzy (seperti AND atau $\mathrm{OR}$ ), $\mathrm{p}_{\mathrm{i}}$ adalah suatu konstanta tegas (crisp) ke-i dan $\mathrm{q}$ merupakan konstanta dalam konsekuen.

\section{B. ANFIS}

ANFIS (adaptive neuro-fuzzy inference system atau adaptive network-based fuzzy inference system) adalah arsitektur yang secara fungsional sama dengan fuzzy rule base model sugeno. Arsitektur ANFIS juga sama dengan jaringan saraf dengan fungsi radial dengan sedikit batasan tertentu [10].

Agar jaringan dengan fungsi basis radial ekuivalen dengan fuzzy berbasis aturan model sugeno orde 1 ini, diperlukan batasan:

a. Keduanya harus memiliki metode agregasi yang sama (rata-rata terbobot atau penjumlahan terbobot) untuk menurunkan semua outputnya.

b. Jumlah fungsi aktivasi harus sama dengan jumlah aturan fuzzy (IF-THEN).

c. Jika ada beberapa input pada basis aturannya, maka tiap-tiap fungsi aktivasi harus sama dengan fungsi keanggotaan tiap-tiap inputnya.

d. Fungsi aktivasi dan aturan-aturan fuzzy harus memiliki fungsi yang sama untuk neuron-neuron dan aturan-aturan yang ada di sisi outputnya [10].

\section{ANFIS untuk Diagnosis Penyakit Jantung}

Berdasarkan 13 masukan yang digunakan pada penelitian ini serta 1 keluaran yang diharapkan, maka dapat dibentuk 5 aturan dengan menggunakan inferensi TSK orde 1. Terdapat 5 aturan karena jumlah cluster ada 5 yang didasarkan pada keluaran, yaitu tingkat resiko penyakit jantung. Berikut ini 5 aturan tersebut:

1. If $\mathrm{x} 1$ is $\mathrm{A} 1$ and $\mathrm{x} 2$ is $\mathrm{B} 1$ and $\mathrm{x} 3$ is $\mathrm{C} 1$ and $\mathrm{x} 4$ is $\mathrm{D} 1$ and $\mathrm{x} 5$ is $\mathrm{E} 1$ and $\times 6$ is $\mathrm{F} 1$ and $\times 7$ is $\mathrm{G} 1$ and $\times 8$ is $\mathrm{H} 1$ and $\mathrm{x} 9$ is $\mathrm{I} 1$ and $\mathrm{x} 10$ is $\mathrm{J} 1$ and $\mathrm{x} 11$ is $\mathrm{K} 1$ and $\mathrm{x} 12$ is $\mathrm{L} 1$ and $\mathrm{x} 13$ is M1 Then $\mathrm{z}=\mathrm{ca} 11 \mathrm{x} 1+$ ca $12 \times 2+$ ca $13 \times 3+$ ca $14 \times 4+$ ca $15 \times 5+$ ca $16 \times 6+$ ca $17 \times 7+$ ca $18 \times 8+$ ca $19 \times 9+$ ca $20 \times 10+$ ca $21 \times 11+$ $\mathrm{ca} 22 \times 12+\mathrm{ca} 23 \times 13+\mathrm{ca} 10$

2. If $\mathrm{x} 1$ is $\mathrm{A} 2$ and $\mathrm{x} 2$ is $\mathrm{B} 2$ and $\mathrm{x} 3$ is $\mathrm{C} 2$ and $\mathrm{x} 4$ is $\mathrm{D} 2$ and $\times 5$ is $\mathrm{E} 2$ and $\times 6$ is $\mathrm{F} 2$ and $\times 7$ is $\mathrm{G} 2$ and $\mathrm{x} 8$ is $\mathrm{H} 2$ and $\mathrm{x} 9$ is $\mathrm{I} 2$ and $\mathrm{x} 10$ is $\mathrm{J} 2$ and $\mathrm{x} 11$ is $\mathrm{K} 2$ and $\mathrm{x} 12$ is $\mathrm{L} 2$ and $\mathrm{x} 13$ is $\mathrm{M} 2$ Then $\mathrm{z}=\operatorname{cb} 11 \mathrm{x} 1+$ cb12x $2+\operatorname{cb} 13 \times 3+\operatorname{cb} 14 \times 4+\operatorname{cb} 15 \times 5+\operatorname{cb} 16 \times 6+$ $\operatorname{cb} 17 \times 7+\operatorname{cb} 18 \times 8+\operatorname{cb} 19 \times 9+\operatorname{cb} 20 \times 10+\operatorname{cb} 21 \times 11$ $+\operatorname{cb} 22 \times 12+\operatorname{cb} 23 \times 13+\operatorname{cb} 10$ 
3. If $\mathrm{x} 1$ is $\mathrm{A} 3$ and $\mathrm{x} 2$ is $\mathrm{B} 3$ and $\mathrm{x} 3$ is $\mathrm{C} 3$ and $\mathrm{x} 4$ is $\mathrm{D} 3$ and $\mathrm{x} 5$ is $\mathrm{E} 3$ and $\mathrm{x} 6$ is $\mathrm{F} 3$ and $\mathrm{x} 7$ is $\mathrm{G} 3$ and $\mathrm{x} 8$ is $\mathrm{H} 3$ and $\mathrm{x} 9$ is $\mathrm{I} 3$ and $\mathrm{x} 10$ is $\mathrm{J} 3$ and $\mathrm{x} 11$ is $\mathrm{K} 3$ and $\mathrm{x} 12$ is $\mathrm{L} 3$ and $\mathrm{x} 13$ is $\mathrm{M} 3$ Then $\mathrm{z}=\mathrm{cc} 11 \mathrm{x} 1+$ $\operatorname{cc} 12 \times 2+\operatorname{cc} 13 \times 3+\operatorname{cc} 14 \times 4+\operatorname{cc} 15 \times 5+\operatorname{cc} 16 \times 6+$ $\operatorname{cc} 17 \times 7+\operatorname{cc} 18 \times 8+\operatorname{cc} 19 \times 9+\operatorname{cc} 20 \times 10+\operatorname{cc} 21 \times 11+$ $\operatorname{cc} 22 \times 12+\operatorname{cc} 23 \times 13+\operatorname{cc} 10$

4. If $\mathrm{x} 1$ is $\mathrm{A} 4$ and $\mathrm{x} 2$ is $\mathrm{B} 4$ and $\mathrm{x} 3$ is $\mathrm{C} 4$ and $\mathrm{x} 4$ is $\mathrm{D} 4$ and $\times 5$ is $\mathrm{E} 4$ and $\times 6$ is $\mathrm{F} 4$ and $\times 7$ is $\mathrm{G} 4$ and $\times 8$ is $\mathrm{H} 4$ and $\mathrm{x} 9$ is $\mathrm{I} 4$ and $\mathrm{x} 10$ is $\mathrm{J} 4$ and $\mathrm{x} 11$ is $\mathrm{K} 4$ and $\mathrm{x} 12$ is $\mathrm{L} 4$ and $\mathrm{x} 13$ is M4 Then $\mathrm{z}=\operatorname{cd} 11 \mathrm{x} 1+$ $\operatorname{cd} 12 \times 2+\operatorname{cd} 13 \times 3+\operatorname{cd} 14 \times 4+\operatorname{cd} 15 \times 5+\operatorname{cd} 16 \times 6+$ $\operatorname{cd} 17 \times 7+\operatorname{cd} 18 \times 8+\operatorname{cd} 19 \times 9+\operatorname{cd} 20 \times 10+\operatorname{cd} 21 \times 11$ $+\operatorname{cd} 22 \times 12+\operatorname{cd} 23 \times 13+\operatorname{cd} 10$

5. If $\mathrm{x} 1$ is $\mathrm{A} 5$ and $\mathrm{x} 2$ is $\mathrm{B} 5$ and $\mathrm{x} 3$ is $\mathrm{C} 5$ and $\mathrm{x} 4$ is D5 and $\mathrm{x} 5$ is $\mathrm{E} 5$ and $\mathrm{x} 6$ is $\mathrm{F} 5$ and $\mathrm{x} 7$ is G5 and $\mathrm{x} 8$ is $\mathrm{H} 5$ and $\mathrm{x} 9$ is $\mathrm{I} 5$ and $\mathrm{x} 10$ is $\mathrm{J} 5$ and $\mathrm{x} 11$ is $\mathrm{K} 5$ and $\mathrm{x} 12$ is L5 and $\mathrm{x} 13$ is M5 Then $\mathrm{z}=$ ce $11 \mathrm{x} 1+$ ce $12 \times 2+\operatorname{ce} 13 \times 3+\operatorname{ce} 14 \times 4+\operatorname{ce} 15 \times 5+\operatorname{ce} 16 \times 6+$ ce $17 \times 7+\operatorname{ce} 18 \times 8+\operatorname{ce} 19 \times 9+\operatorname{ce} 20 \times 10+\operatorname{ce} 21 \times 11+$ ce $22 \times 12+\operatorname{ce} 23 \times 13+\operatorname{ce} 10$

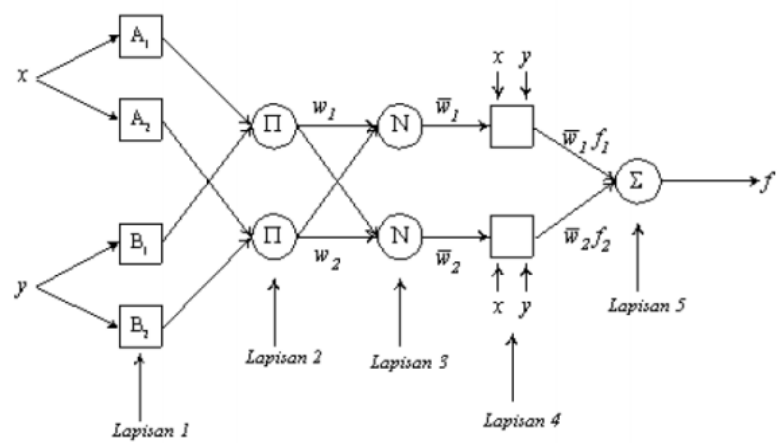

Gambar 1. Arsitektur Jaringan ANFIS [11]

Jaringan ANFIS terdiri dari lima lapisan [10]. Gambar 1 menunjukkan arsitektur jaringan ANFIS. Berikut ini penjelasan tiap lapisan jaringan ANFIS yang diimplementasikan pada sistem diagnosa penyakit jantung:

a. Keluaran dari tiap neuron pada lapisan pertama merupakan derajat keanggotaan dari fungsi keanggotaan yang diberikan oleh masukan. Fungsi yang digunakan pada penelitian ini adalah kurva bell dengan fungsi beta dan gauss. Persamaan 1 merupakan fungsi Beta dan persamaan 2 merupakan fungsi Gauss.

$$
\begin{aligned}
& B(x, c, \sigma)=\frac{1}{1+\left(\frac{x-c}{\sigma}\right)^{2}} \\
& G(x, \gamma, \beta)=e^{-\frac{1}{2}\left(\frac{x-c}{\sigma}\right)^{2}}
\end{aligned}
$$

dimana c (mean), $\sigma$ (standart deviation) merepresentasikan pusat dan lebar setiap fungsi [7].

b. Tiap neuron pada lapisan kedua berupa neuron tetap yang outputnya adalah fire strength tiap aturan. Operator yang digunakan disini adalah operator AND.

c. Tiap neuron pada lapisan ketiga merupakan hasil perhitungan rasio dari $\alpha$ predikat (w), dari aturan ke-i terhadap jumlah dari keseluruhan $\alpha$ predikat. $\overline{W_{l}}=\frac{W_{i}}{W_{1}+W_{2}}$, dengan $\mathrm{i}=1,2,3,4,5$

Hasil ini dinamakan normalised fire strength.

d. Pada lapisan keempat, tiap neuron merupakan node adaptif terhadap suatu keluaran.

$\overline{W_{i}} y_{i}=\overline{W_{a}}(\operatorname{ci} 11 \times 1+\operatorname{ci} 12 \times 2+\operatorname{ci} 13 \times 3+\operatorname{ci} 14 \times 4+$ $\operatorname{ci} 15 \times 5+\operatorname{ci} 16 \times 6+\operatorname{ci} 17 \times 7+\operatorname{ci} 18 \times 8+\operatorname{ci} 19 \times 9+$ $\operatorname{ci} 20 \times 10+\operatorname{ci} 21 \times 11+\operatorname{ci} 22 \times 12+\operatorname{ci} 23 \times 13+\operatorname{ci} 10)$, dengan $\mathrm{i}=1,2,3,4,5$, sedangkan $\overline{W_{2}}$ adalah normalised fire strength pada lapisan ke tiga dan $\{$ ci11, ci12, ci13,..., ci10\} merupakan consequent parameter.

e. Tiap neuron pada lapisan kelima adalah node tetap yang merupakan penjumlahan dari semua masukan dari lapisan sebelumnya.

\section{UJI COBA DAN EVALUASI}

Proses uji coba sistem menggunakan data UCI cleveland sebanyak 297 data yang memiliki 13 atribut untuk input dan 1 atribut untuk output. Terdapat 4 jenis uji coba yang dilakukan, yaitu uji coba pengaruh laju pembelajaran (learning rate) terhadap sistem, uji coba pengaruh terasi (Epoch) terhadap sistem, uji coba pengaruh error minimum terhadap sistem, serta uji coba pengaruh membership function terhadap sistem.

$$
\text { akurasi }=\frac{\text { jumlah data diagnosis benar }}{\text { total keseluruhan data diagnosis }}
$$

Sebagai evaluasi, semua hasil pengujian ini diukur menggunakan akurasi dengan rumusan pada persamaan 3. Jumlah data diagnosis benar merupakan jumlah hasil diagnosis sistem yang sesuai dengan data obeservasi pada UCI Cleveland. Sedangkan total keselurusan data diagnosis pada penelitian ini sebanyak 297 data.

Tabel 1. Evaluasi Pengaruh Iterasi

\begin{tabular}{ccccc}
\hline \multirow{2}{*}{ Iterasi Max } & \multirow{2}{*}{$\begin{array}{c}\text { Error } \\
\text { Min }\end{array}$} & Learning Rate & \multicolumn{2}{c}{ Akurasi (\%) } \\
\cline { 4 - 5 } & 0,0001 & 0,9 & gauss & Beta \\
\hline $\mathbf{1 0 0}$ & 0,0001 & 0,9 & $\mathbf{6 2 , 6 3}$ & $\mathbf{6 5 , 6 6}$ \\
\hline $\mathbf{2 0 0}$ & 0,03 & $\mathbf{6 5 , 6 6}$ \\
\hline
\end{tabular}


Tabel 2 Evaluasi Pengaruh Error Minimum

\begin{tabular}{ccccc}
\hline \multirow{2}{*}{ Iterasi Max } & \multirow{2}{*}{$\begin{array}{c}\text { Error } \\
\text { Min }\end{array}$} & Learning Rate & \multicolumn{2}{c}{ Akurasi (\%) } \\
\cline { 4 - 5 } & & & Gauss & Beta \\
\hline 100 & $\mathbf{0 , 0 0 1}$ & 0,9 & $\mathbf{6 2 , 6 7}$ & $\mathbf{6 5 , 6 6}$ \\
\hline 100 & $\mathbf{0 , 0 0 0 1}$ & 0,9 & $\mathbf{6 2 , 6 7}$ & $\mathbf{6 5 , 6 6}$ \\
\hline
\end{tabular}

Tabel 1 menunjukkan evaluasi uji coba pengaruh iterasi (epoch) terhadap sistem. Nilai iterasi yang diujikan adalah 100 dan 200. Evaluasi uji coba pengaruh nilai error terhadap sistem ditunjukkan pada Error! Reference source not found. dengan nilai error yang diujikan adalah 0,001 da 0,0001. Sedangkan Tabel 3 menunjukkan evaluasi pengaruh learning rate terhadap sistem. Nilai yang diujikan mulai dari 0,1 hingga 0,9 .

Tabel 3 Evaluasi Pengaruh Learning Rate

\begin{tabular}{ccccc}
\hline \multirow{2}{*}{ Iterasi Max } & \multirow{2}{*}{$\begin{array}{c}\text { Eror } \\
\text { Min }\end{array}$} & Learning Rate & \multicolumn{2}{c}{ Akurasi (\%) } \\
\cline { 4 - 5 } & 0,0001 & $\mathbf{0 , 1}$ & $\mathbf{6 2 , 6 3}$ & $\mathbf{6 5 , 6 6}$ \\
\hline 100 & 0,0001 & $\mathbf{0 , 2}$ & $\mathbf{6 2 , 6 3}$ & $\mathbf{6 5 , 6 6}$ \\
\hline 100 & 0,0001 & $\mathbf{0 , 3}$ & $\mathbf{6 2 , 6 3}$ & $\mathbf{6 5 , 6 6}$ \\
\hline 100 & 0,0001 & $\mathbf{0 , 4}$ & $\mathbf{6 2 , 6 3}$ & $\mathbf{6 5 , 6 6}$ \\
\hline 100 & 0,0001 & $\mathbf{0 , 5}$ & $\mathbf{6 2 , 6 3}$ & $\mathbf{6 5 , 6 6}$ \\
\hline 100 & 0,0001 & $\mathbf{0 , 6}$ & $\mathbf{6 2 , 6 3}$ & $\mathbf{6 5 , 6 6}$ \\
\hline 100 & 0,0001 & $\mathbf{0 , 7}$ & $\mathbf{6 2 , 6 3}$ & $\mathbf{6 5 , 6 6}$ \\
\hline 100 & 0,0001 & $\mathbf{0 , 8}$ & $\mathbf{6 2 , 6 3}$ & $\mathbf{6 5 , 6 6}$ \\
\hline 100 & 0,0001 & $\mathbf{0 , 9}$ & $\mathbf{6 2 , 6 3}$ & $\mathbf{6 5 , 6 6}$ \\
\hline 100 & & & &
\end{tabular}

Hasil akurasi pada Tabel 1, Error! Reference source not found., dan Tabel 3 tersebut menunjukkan bahwa tidak ada perbedaan nilai akurasi sistem untuk variasi nilai iterasi (epoch), error, dan learning rate yang diujikan baik menggunakan fungsi keanggotaan Gauss maupun Beta. Tampak pula bahwa hasil akurasi sistem menggunakan fungsi keanggotaan Beta $(65,66 \%)$ lebih tinggi dibandingkan dengan menggunakan fungsi keanggotaan Gauss $(62,63 \%)$.

\section{KESIMPULAN}

Dari hasil uji coba yang didapatkan, didapatkan beberapa kesimpulan sebagai berikut:

1. Perubahan nilai learning rate, epoch, dan error min tidak memberikan pengaruh terhadap nilai akurasi pada kasus dengan data UCI cleveland (297 data)

2. Penggunaan membership function yang berbeda mempengaruhi tingkat akurasi, dengan hasil sebagai berikut:

Beta : 65,66\%

Gauss : $62,63 \%$

3. Penggunaan membership function Beta menghasilkan tingkat akurasi lebih baik yaitu $65,66 \%$.

\section{REFERENSI}

[1]. Novruz allahverdi, serhat torun, ismail saritas, 2007. Design of a fuzzy expert system for determination of coronary heart disease risk, International Conference on Computer Systems and Technologies.

[2]. Kemal Polata, Salih Günessa, Sülayman Tosunb, 2007. Diagnosis of heart disease using artificial immune recognition system and fuzzy weighted pre-processing. Elsevier, Pattern Recognition.

[3]. M. Nikravesh, Janusz, Lotfi A. Zadeh, 2007. Foring New Frontier: Fuzzy Pioneer I, Springer.

[4]. Ali.Adeli, Mehdi.Neshat, 2010. A Fuzzy Expert System for Heart Disease Diagnosis, IMECS (International MultiConference of Engineers and Computer Scientists).

[5]. P.K. Anooj, 2011. Clinical decision support system: Risk level prediction of heart disease using weighted fuzzy rules. Elsevier Ltd.

[6]. E. P. Ephzibah, Dr. V. Sundarapandian. 2012. An Expert System for Heart Disease Diagnosis Using Neuro-Fuzzy Technique. IJSCAI (International Journal on Soft Computing, Artificial Intelligence and Applications).

[7]. Dr. A.V Senthil Kumar, 2013. Diagnosis of Heart Disease Using Advanced Fuzzy Resolution Mechanism. IJSAIT (International Journal of Science and Applied Information Technology).

[8]. Jantzen, Jan. 1998. Neuro Fuzzy Modelling. http://www.iau.dtu.dk/ jj/pubs/nfmod.pdf.

[9]. Ephzibah, E.P., 2010. Cost effective approach on feature selection using genetic algorithms and LS-SVM classifier. IJCA, EC OT.55, pp. 55-56.

[10]. Sri Kusumadewi, Sri Hartanti. 2010. Neuro-Fuzzy: Integrasi Sistem Fuzzy dan Jaringan Syaraf, Edisi 2. Graha Ilmu.

[11]. Jang, J.S.R., Sun C.T., and Mizutani E. 1997. Neuro-Fuzzy and Soft Computing, Prentice-Hall. New Jersey 